\title{
Pediatric trauma BIG score: Predicting mortality in polytraumatized pediatric patients
}

\author{
Mohamed Abd El-Aziz El-Gamasy, Ahmed Abd El Basset Abo Elezz, \\ Ahmed Sobhy Mohamed Basuni ${ }^{1}$, Mohamed El Sayed Ali Abd Elrazek
}
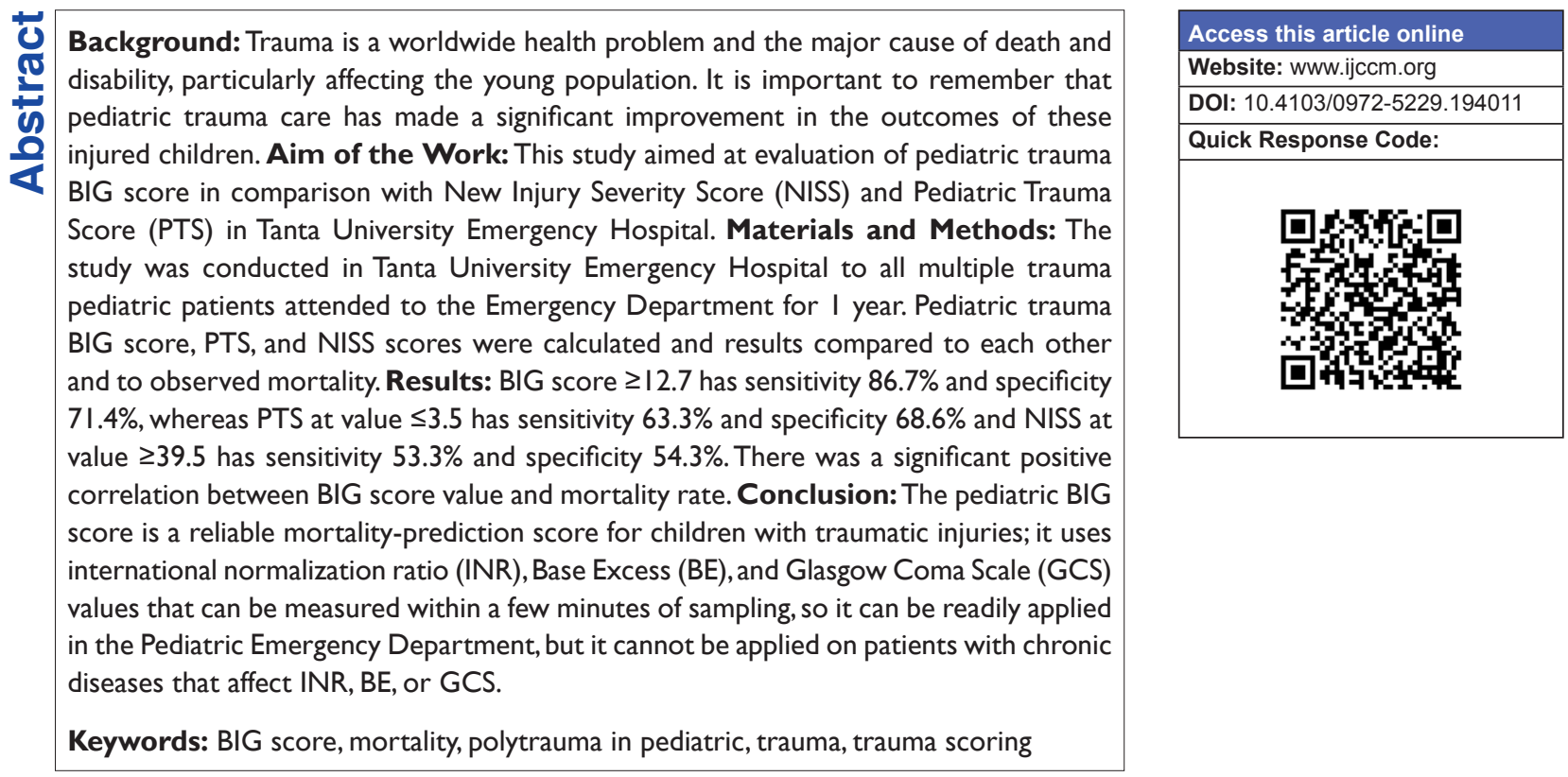

\section{Introduction}

Trauma is the most serious and major health problem in developing countries. Recently, several trauma scoring systems have been validated for prediction of patient survival, ${ }^{[1]}$ New Injury Severity Score (NISS) is defined as the sum of the squares of the Abbreviated Injury Scale (AIS) of each of the patient's most severe AIS injuries irrespective of the body region in which they occur. ${ }^{[2]}$ The Pediatric Trauma Score (PTS) was

From:

Departments of Pediatrics and Anathesia and Intensive Care Unit ${ }^{1}$ Faculty of Medicine,Tanta University, Tanta, Egypt

\section{Correspondence:}

Dr. Mohamed Abd El-Aziz El-Gamasy, Departement of Pediatrics,Tanta Faculty of Medicine, El-Geish Street, Tanta, Gharbia Governate, Egypt. E-mail: mgamsy@gmail.com devised specifically for the triage of pediatric trauma patients. ${ }^{[3]}$ The pediatric BIG score can be performed rapidly on admission to evaluate the severity of illness and to predict mortality in children with traumatic injuries. ${ }^{[4]}$ International normalization ratio (INR) is a measure of tissue factor-activated arm of the coagulation cascade, coagulopathy, as characterized by increased

This is an open access article distributed under the terms of the Creative Commons Attribution-NonCommercial-ShareAlike 3.0 License, which allows others to remix, tweak, and build upon the work non-commercially, as long as the author is credited and the new creations are licensed under the identical terms.

For reprints contact: reprints@ medknow.com

How to cite this article: El-Gamasy MA, Elezz AA, Basuni AS, Elrazek ME. Pediatric trauma BIG score: Predicting mortality in polytraumatized pediatric patients. Indian J Crit Care Med 2016;20:640-6. 
fibrin degradation products, has been shown to predict mortality in children with head trauma ${ }^{[5]}$ while base deficit is a measure of shock and acidosis. A BIG score of $<12$ points suggests a mortality of $<5 \%$, whereas a cutoff of $>26$ points corresponds to a mortality of $>50 \%{ }^{[6]}$ The limitation of the BIG score is that it requires laboratory values to calculate it. ${ }^{[4]}$

This study aimed at evaluation of pediatric trauma BIG score in comparison with NISS and PTS in Tanta University Emergency Hospital.

\section{Materials and Methods}

The study was conducted as a prospective comparative study in a University Emergency Hospital in Egypt for 1 year from February 2014 to February 2015, on fifty multiple trauma pediatric patients admitted to the Pediatric Emergency Department.

\section{Inclusion criteria}

All pediatric patients between 1 and 18 years old and within $24 \mathrm{~h}$ after trauma were included in the study.

\section{Exclusion criteria}

Patients $<1$ year old, patients who came to the hospital after $24 \mathrm{~h}$ of occurrence of trauma, burn, and electric shock without polytrauma, and patients with chronic diseases such as chronic renal failure, hepatic, hematologic, or neurologic diseases were excluded from the study.

Data collected for each multiple trauma patient attended to Emergency Department, include history taking stressing on mechanism of injury, thorough clinical examination, especially systolic blood pressure (SBP), pulse rate, respiratory rate, Glasgow Coma Scale (GCS), and laboratory investigations including arterial blood gas, prothrombin time, partial thromboplastin time, and INR.

PTS was calculated by PTS was calculated by summation of these variables [Table A]. ${ }^{[7]}$

NISS was calculated by summation of square of AIS score of the most three affected regions of body regardless site of injury as follows: NISS $=(\text { AIS1 })^{2}+(\text { AIS2 })^{2}+(\text { AIS3 })^{2}$ [Table B]. ${ }^{[7]}$

Pediatric trauma BIG score then was calculated as follows:

Pediatric BIG score equation = (Admission base deficit $)+(2.5 \times$ INR $)+(15-$ GCS $)$.
This equation can then be implemented into a mortality-predicting formula:

Predicted mortality $=1 /\left(1+e^{-x}\right)$, where $x=0.2 \times$ (BIG score) - 5.208.

Thirty-day mortality was used as the primary outcome parameter of our analysis.

Testing the mortality prediction of the BIG score on our trauma patients and compared observed and expected mortality by BIG score.

Comparing between BIG score, PTS, and NISS as regard validity and observed outcome.

Trauma management at patient arrival includes primary then secondary survey in the first 10-15 $\mathrm{min}$. Primary survey aims simultaneous assessment and treatment of life-threatening injuries. Initial observations of the patient as he or she was being wheeled in by emergency medical service (EMS), airway was evaluated with cervical spine precautions, assisted bag valve mask ventilation may be indicated, assess the breathing. Evaluation of chest wall motion, lung sounds, respiratory rate, and oxygen saturation was done. Early intubation was done for poor respiratory effort, inadequate oxygenation, or GCS score of eight or less.

For assessment of the circulation, examination of Focused Assessment Sonography In Trauma(FAST) and two large -bore aintravenous acess were established. Neurologic assessment was done by assessment of

Table (A): Variables for calculation of Pediatric Trauma Score(PTS) (Citated from Emergency Medical Journal $201 \mathrm{I})^{[7]}$

\begin{tabular}{llll}
\hline Variables & +2 & + I & - I \\
\hline Weight $(\mathrm{kg})$ & $>20$ & $12-20$ & $<10$ \\
Systolic blood & $>90$ & $50-90$ & $<50$ \\
pressure (mmHg) & & & \\
Mental status & Awake & LOC & Unresponsive \\
Airway & Patent & Maintainable & Unmaintainable \\
Skeletal fracture & None & Closed or suspected & Multiple closed or open \\
Open wounds & None & Minor & Major or penetrating \\
\hline
\end{tabular}

Table (B): Abbreviated Injury Scale of New Injury Severity Score (NISS) (Citated from Emergency Medical Journal $20 \mathrm{II})^{[7]}$

\begin{tabular}{lc}
\hline Abbreviated Injury Scale & Injury \\
\hline Minor & 1 \\
Moderate & 2 \\
Serious & 3 \\
Severe & 4 \\
Critical & 5 \\
Unsurvivable & 6 \\
\hline
\end{tabular}


GCS score. Pitfalls included "lucid interval." ${ }^{[7]}$ Brief synopsis of what happened, asking about prehospital vitals. ${ }^{[7]}$ Effort was made to maintain body temperature as hypothermic patients have worse outcomes. ${ }^{[7]}$

RoutineimagingstudiesincludechestX-ray, anteroposterior, pelvis, and lateral cervical spine. Computed tomography scan of the cervical spine, FAST or extended-FAST to evaluate for intraperitoneal blood, pneumothorax, and hemothorax as well. ${ }^{[7]}$ A Foley catheter was placed for evaluation for hematuria as well as monitoring urine output. Rectal examination was done before placement to evaluate for signs of urethral injury such as high-riding prostate as well as blood at the urethral meatus. ${ }^{[7]}$

Secondary assessment is an organized, head-to-toe assessment, especially difficult to see areas such as the axillae and perineum. ${ }^{[7]}$

Signs/symptoms, allergies, medications, past medical history, last meal, and events history was obtained from the patient, family, or EMS. ${ }^{[7]}$

By this time, the initial resuscitation and stabilization of most patients were completed, and the patient was ready to leave the trauma bay to (a) the operating room if immediate surgery was indicated, (b) the imaging suite if he or she was stable, (c) the Intensive Care Unit if observation was the planned course of action, or (d) a regular gurney/stretcher in the Emergency Department for observation before discharge home. ${ }^{[7]}$

\section{Statistical analysis}

The collected data were analyzed using SPSS version 20 software (SPSS Inc., Chicago, IL, USA) and Microstat-W software (India, CNET download.com). Categorical data were presented as number and percentages whereas quantitative data were expressed as a mean \pm standard deviation. Chi-square test, Fisher's exact test, Z-test, Student's $t$-test, Mann-Whitney U-test, and McNemar's test were used as tests of significance. Receiver operating characteristic (ROC) curve was used to determine cutoff values of the studied mortality scores with optimum sensitivity and specificity. Binary logistic regression model was used to detect the significant predictors of mortality and to design an equation for predicted mortality from BIG score. The accepted level of significance in this work was stated at $0.05(P<0.05$ was considered significant). ${ }^{[8]} P>0.05$ is nonsignificant, $P<0.05$ is significant, and $P \leq 0.001$ is highly significant.

\section{Results}

This study was done on fifty polytraumatized children. Age ranged from 1 to 16 years, $48 \%$ males and 52\% females. Mortality rate was $30 \%$. Table 1 shows that there was a significant decrease in the age, body weight, SBP, and GCS and a significant increase in both INR and base excess of nonsurvivor patients when compared to survivor patients.

Table 2 and Figure 1 show trauma characteristics of the studied children as regard systems injured by trauma, regarding airway, 11 patients were with patent airway, 28 patients with maintainable airway, and 11 patients unmaintainable airway.

Table I: Demographic, clinical, and laboratory variables as regard patient outcomes

\begin{tabular}{lcccc}
\hline Variable & \multicolumn{2}{c}{ Mean \pm SD } & $\begin{array}{c}\text { Student's } \\
\text { t-test }\end{array}$ & $P$ \\
\cline { 2 - 3 } & $\begin{array}{c}\text { Nonsurvivors } \\
(\boldsymbol{n}=15)\end{array}$ & $\begin{array}{c}\text { Survivos } \\
(\boldsymbol{n}=35)\end{array}$ & & \\
\hline Age & $5.2 \pm 5.3$ & $9.9 \pm 5.22$ & 2.57 & $0.012(\mathrm{~S})$ \\
Body weight & $24.7 \pm 18.6$ & $40.1 \pm 17.3$ & 2.54 & $0.011(\mathrm{~S})$ \\
SBP & $79.3 \pm 24.91$ & $97.1 \pm 16.37$ & 2.99 & $0.004(\mathrm{~S})$ \\
GCS & $4.8 \pm 1.59$ & $10.6 \pm 3.71$ & 4.88 & $<0.001(\mathrm{HS})$ \\
INR & $1.23 \pm 0.12$ & $1.15 \pm 0.08$ & 3.0 & $0.004(\mathrm{~S})$ \\
Base excess/deficit & $7.58 \pm 6.12$ & $2.37 \pm 1.44$ & 2.06 & $0.039(\mathrm{~S})$ \\
\hline
\end{tabular}

SBP: Systolic blood pressure; GCS: Glasgow Coma Scale; INR: International normalization ratio; HS: Highly significant; S: Significant; SD: Standard deviation

Table 2: Trauma characteristics of the studied children as regard patient outcomes

\begin{tabular}{|c|c|c|c|c|c|c|}
\hline & \multicolumn{2}{|c|}{ Nonsurvivors } & \multicolumn{2}{|c|}{ Survivors } & \multicolumn{2}{|c|}{$\begin{array}{c}\text { Total } \\
\text { number }\end{array}$} \\
\hline & $n=15$ & $30 \%$ & $n=35$ & $70 \%$ & $n=50$ & $100 \%$ \\
\hline \multicolumn{7}{|l|}{$\begin{array}{l}\text { System injured by } \\
\text { trauma }\end{array}$} \\
\hline \multicolumn{7}{|l|}{ Airway condition } \\
\hline Patent & 0 & 0 & 11 & 22 & 11 & 22 \\
\hline Maintainable & 8 & 16 & 20 & 40 & 28 & 56 \\
\hline Unmaintainable & 7 & 14 & 4 & 8 & 11 & 22 \\
\hline \multicolumn{7}{|l|}{ CNS (head trauma) } \\
\hline Awake & 0 & 0 & 17 & 34 & 17 & 34 \\
\hline Comatosed & 15 & 30 & 18 & 36 & 33 & 66 \\
\hline \multicolumn{7}{|l|}{ Mechanism of injury } \\
\hline Fall from height & 4 & 8 & 18 & 36 & 22 & 44 \\
\hline Pedestrian collision & 5 & 10 & 5 & 10 & 10 & 20 \\
\hline MVA & 2 & 4 & 8 & 16 & 10 & 20 \\
\hline Motorcycle & 4 & 8 & 4 & 8 & 8 & 16 \\
\hline \multicolumn{7}{|l|}{$\begin{array}{l}\text { Diagnosis causes of } \\
\text { death }\end{array}$} \\
\hline $\begin{array}{l}\text { CNS failure (brain } \\
\text { death) }\end{array}$ & 10 & 20 & - & - & 50 & 100 \\
\hline Respiratory failure & I & 2 & - & - & & \\
\hline Hemorrhagic shock & 3 & 6 & - & - & & \\
\hline $\begin{array}{l}\text { Multiple system } \\
\text { organ failure }\end{array}$ & 1 & 2 & - & - & & \\
\hline Total & 15 & 30 & 35 & 70 & & \\
\hline
\end{tabular}


Regarding level of consciousness, 17 patients were awake and 33 patients were comatosed.

Table 2 also and Figure 2 show that the most common mechanism of injury among studied patients was fall from height by $44 \%$, and motorcycle was the least common mechanism of injury by $16 \%$. They show also that the most favorable prognosis was in fall from height, and the poorest prognosis was in both pedestrian collision and motorcycle. Table 2 also shows that the most common diagnosis of cause of death among studied patients was central nervous system lesion (brain death) $(20 \%)$, followed by hemorrhagic shock $(6 \%)$ while respiratory failure and multiple system organ failure were the least common diagnosis of cause of death ( $2 \%$ for each).

Figure 3 shows no significant difference between mean value of NISS among died and survived patients, whereas there was a significant increase in mean value of PTS among survived patients and a significant decrease in mean value of BIG score among survived patients.

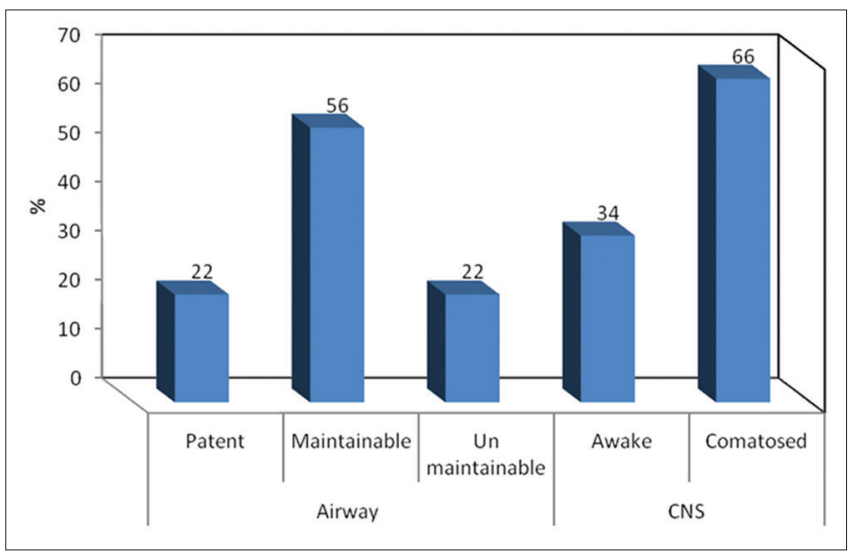

Figure I: Comparison between airway and central nervous system status among studied patients

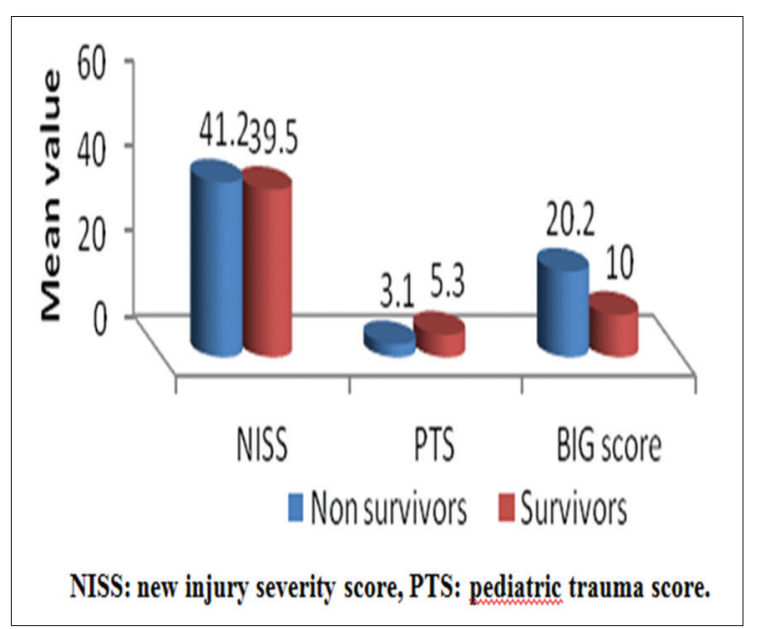

Figure 3: Comparing survivors and nonsurvivors regarding trauma scores
Figure 4 compares ROC curve for validity of the three studied trauma scores (BIG, PTS, and NISS) in prediction of mortality, BIG score $\geq 12.7$ has sensitivity $86.7 \%$, specificity $71.4 \%$, positive predictive value (PPV) 56.5\%, negative predictive value (NPV) $92.6 \%$, and confidence index (CI) $0.77-0.97$, whereas PTS at value $\leq 3.5$ has sensitivity $63.3 \%$, specificity $68.6 \%$, PPV $42.2 \%$, NPV $77.4 \%$, and CI $0.57-0.85$ and NISS at value $\geq 39.5$ has sensitivity $53.3 \%$, specificity $54.3 \%$, PPV $33.3 \%$, NPV 73.1\%, and CI 0.48-0.79. Hence, the highest sensitivity and specificity of the three studied scores was to BIG score at cutoff value of $\geq 12.7$, while the lowest sensitivity and specificity was to NISS at cutoff value NISS $\geq 39.5$, while PTS showing moderate specificity and sensitivity at cutoff value $\leq 3.5$. Figure 4 shows also that areas under the ROC curve of NISS, PTS, and BIG were $0.87,0.71$, and 0.63 respectively.

Table 3 and Figure 5 show relation of BIG Score to observed mortality rate, there was a significant positive correlation between BIG score values and mortality

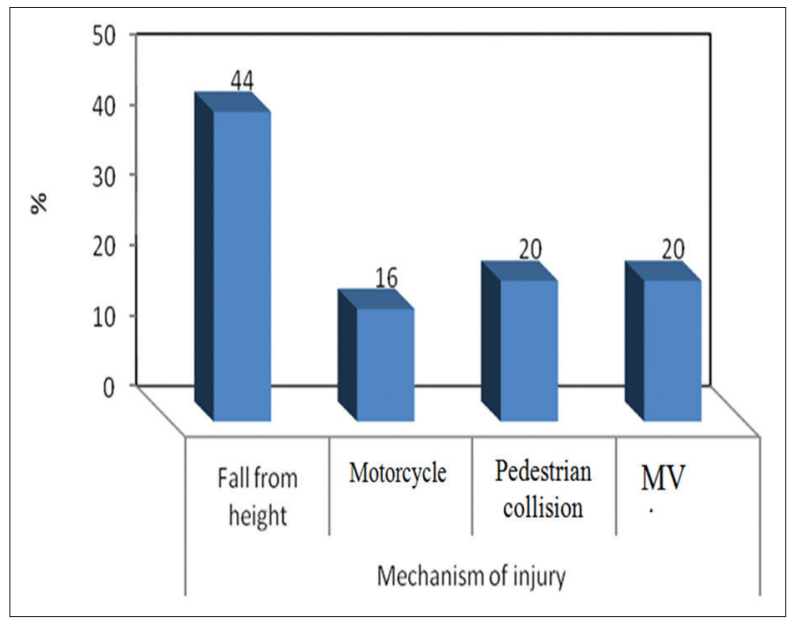

Figure 2: Mechanism of injury among studied patients

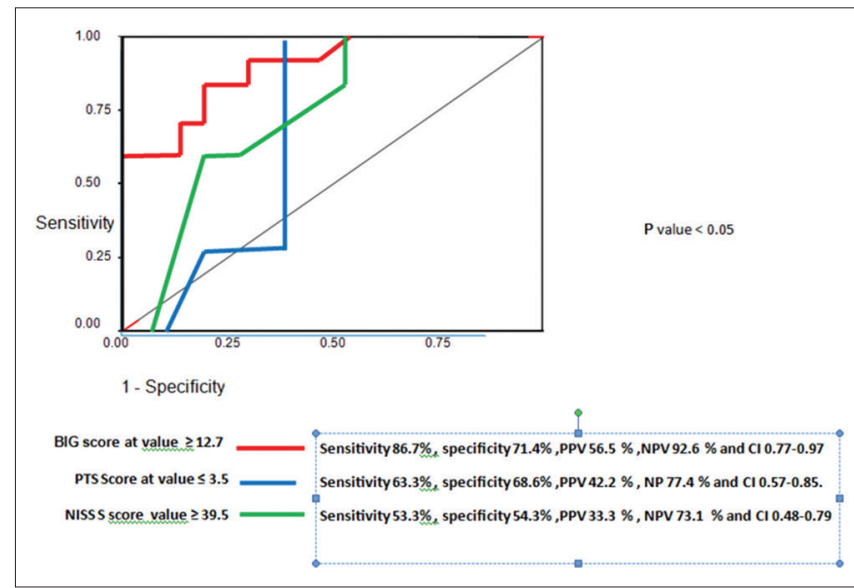

Figure 4: Receiver operating characteristic curves for the validity of BIG, Pediatric Trauma Score, and New Injury Severity Score trauma scores in prediction of mortality 


\begin{tabular}{|c|c|c|c|}
\hline \multirow[t]{2}{*}{ BIG score } & \multicolumn{2}{|c|}{ Nonsurvivors } & \multirow[t]{2}{*}{ Predicted/observed (\%) } \\
\hline & Observed & Predicted & \\
\hline$\overline{<1.5}$ & 0 & 0 & - \\
\hline $1.5-5$ & 0 & 0 & - \\
\hline $5-10$ & 0 & 0 & - \\
\hline $10-16$ & 7 & 5 & 71 \\
\hline$>16$ & 8 & 7 & 87.5 \\
\hline Total & 15 & 12 & 80 \\
\hline
\end{tabular}

Fisher's exact test $=21.7 ; P<0.00 \mathrm{I}(\mathrm{HS})$. HS: Highly significant

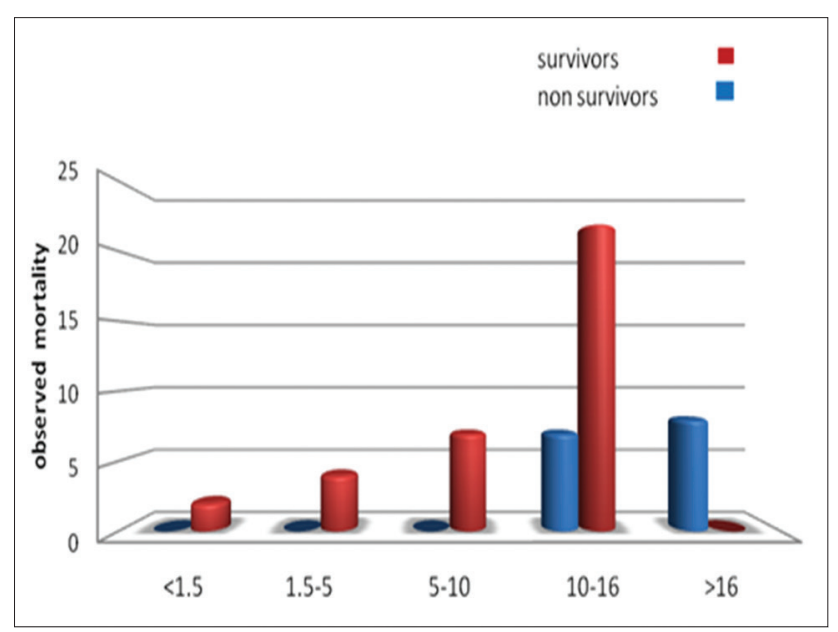

Figure 5: Relation of BIG score to observed mortality rate

rates as the higher the value of BIG score, the higher the incidence of mortality.

\section{Discussion}

Easy-to-use trauma scoring systems inform physicians of the severity of trauma in patients and help them decide the course of trauma management. The use of trauma scoring systems can be used before the patient reaches the hospital, to decide whether to send the patient to a trauma center, and can also be used for clinical decision-making when the trauma patient has just arrived at the Emergency Department (ED). When the patient is in the ED, trauma scoring systems can be used to prepare the patient for surgery, to call on medical staff for trauma support, and to inform the family of the severity of the patient's condition in the early stage..$^{[9]}$

In the present prospective comparative study, pediatric trauma BIG score, PTS, and NISS scale, has been conducted on fifty polytraumatized pediatric patients attended to Tanta emergency university hospital. In this study, we choose to register the subjects from only one center to avoid the possible variability in the triage system in different settings. The mortality rate was $30 \%$ of the patients. As regarding mechanism of injury, we found that fall from height was the most common cause of admission in polytraumatized pediatric patients $(44 \%)$ and this coincide with the study done by Fiorentino et al. in Hospital de Niño "Ricardo Gutiérrez" in Sao Paolo (54\%). ${ }^{[10]}$ Another study made by Derakhshanfar et al. found that pedestrian car accidents and falling down were the most common causes of injuries $(23.3 \%$ and $21.3 \%)$, respectively. ${ }^{[11]}$ Letts et al. in their study on The Children's Hospital of Eastern Ontario, a major pediatric trauma center, found that fall from height was the third common cause of trauma in children was by $14 \%$ and the most common cause was motor car accidents by $38.9 \% .{ }^{[12]}$

In this study as regarding the age of patients, there was a significant decrease in age of nonsurvivors when compared to survivors $(P=0.01)$. It was against the study made by Nakayama et al. concluded that survival after childhood injury is independent on the age groups in their study after controlling injury severity. ${ }^{[13]}$

In the present study as regarding body weight, there was a significant decrease in body weight in nonsurvivors and when compared to survivors $(P=0.011)$. It was against the study made by Derakhshanfar et al. who found that there was no significant relation between body weight of patients and their outcome. ${ }^{[1]}$

As regarding SBP, we found a significant decrease in SBP in nonsurvivors when compared to survivors $(P=0.004)$.

Vallipakorn et al. conducted their cross-sectional study included injured children from 34 emergency services showed that when compared with children with normal relative risk (RR) and SBP, children with an abnormal SBP and RR had a 5.0 (95\% CI: 3.9-6.4) and 2.2 (95\% CI: 1.5-3.1) times higher odds of death, respectively. ${ }^{[14]}$

Derakhshanfar et al. conducted their study in Tehran, Iran, on 151 pediatric trauma patients and showed that the mean SBP was $96 \pm 11 \mathrm{mmHg} \cdot{ }^{[11]}$

There have been several previous studies on the importance of $\mathrm{BE}$ in evaluating trauma patients, but only a few examined its importance in the pediatric population. ${ }^{[14]}$ Those studies suggested that BE was a good indicator of injury severity in pediatric trauma patients. In this work, we found that there was a significant increase in $\mathrm{BE}$ in nonsurvivors when compared to survivors $(P=0.039)$.

Kincaid et al. found that admission BE reflected injury severity. ${ }^{[15]}$ 
Randolph et al. found that admission BE was a strong indicator of injury severity, and a BE below -5 was predictive of severe injury and mortality. ${ }^{[16]}$

In severely injured children (all requiring mechanical ventilation), $\mathrm{BE}<-8$ predicted a higher incidence of infectious complications and a less favorable outcome. ${ }^{[16]}$

Borgman et al. reported that admission base deficit was also found to be an independent predictor of mortality in 707 children injured in Iraq and Afghanistan. ${ }^{[4]}$

GCS is the most widely used scoring system for the evaluation of disorder of consciousness. It was developed by Teasdale and Jennett in $1974 . .^{[17]}$ The modified GCS is used for infants and young children to obtain the most accurate score. ${ }^{[18]}$

In this study, there was a significant decrease in GCS of nonsurvivor patients when compared to survivor patients. Most of the cases of death (66\%) were due to head trauma, so GCS work better in these cases than other causes of death such as other, hemorrhagic shock, respiratory failure, or multiple system organ injury. This coincides with a study made by Gill et al. that proved that GCS provides a prediction about morbidity and mortality after head injury. ${ }^{[19]}$

In this study, there was a significant increase in INR of nonsurvivor patients when compared to survivor patients. That increases specificity and accuracy of BIG score in predicting mortality.

Hess et al. ${ }^{[20]}$ found that abnormal coagulation tests were increasingly frequent with increasing injury severity. Verma and Kole study showed that INR is indeed a good predictor of mortality in trauma patients, with a high diagnostic accuracy. ${ }^{[21]}$

In this study, PTS showing moderate specificity and sensitivity at cutoff value $\leq 3.5$ with sensitivity $63.3 \%$ and specificity $68.6 \%$. There are conflicting reports on the effectiveness of the PTS as a tool for assessing prognosis and in identifying those who will need a transfer to a pediatric trauma center. Narci et al. studied the prognostic value of PTS in pediatric trauma patients on 151 pediatric patients in Tehran and found it to be an independent predictor of morbidity. ${ }^{[22]}$ Kaufmann et al. reported that the PTS has no advantage in children, even in children younger than 14 years. ${ }^{[23]}$ Another study made by Eichelberger et al. has reported no difference between the predictive capabilities of the trauma score and the PTS in identifying severely injured children. ${ }^{[24]}$ Further refinements of the PTS include the age-specific PTS and the triage age-specific PTS. These scoring systems, however, have not yet been validated and are rarely used.

In 1997, a simple modification of injury severity score (ISS) was formulated by Osler et al. and referred to as the NISS, ${ }^{[25]}$ In the present study, we found that NISS at cutoff value $\leq 39.5$ has sensitivity $53.3 \%$ and specificity $54.3 \%$ for predicting mortality. Sullivan et al. found that The NISS performs as well as the ISS in predicting mortality in pediatric trauma patients who are not severely injured (ISS <24). ${ }^{[26]}$

NISS has disadvantage of not taking physiologic derangements or chronic health into account. It is not intended to reflect patient outcomes, but only to score an individual injury. ${ }^{[10]}$

An adult trauma study made by Brockamp et al., to compare the BIG score with other trauma scores revealed that BIG score is a good predictor of mortality in the adult trauma population, ${ }^{[27]}$ and they added that in a penetrating trauma population, the BIG score performed better than in a population with blunt trauma. The BIG score has the advantage of being available shortly after admission and may be used to predict clinical prognosis or as a research tool to risk stratify trauma patients into clinical trials. ${ }^{[27]}$

In the present study, we found that pediatric trauma BIG score was more sensitive and specific and easily applicable score in predicting mortality than PTS and NISS, and this coincides with the study done by Borgman et al. ${ }^{[4]}$

\section{Conclusion}

Paediatric trauma BIG score may be applied as a mortality prediction tool in pediatric emergency for its ease and simplicity of application at the time of entry at the Emergency department. This would also help in evaluating for early invasive monitoring and treatment decisions in the Intensive Care unit.

\section{Recommendation}

We recommend that leaflets for BIG score be formed and calculated easily in the Emergency Department to help predicting mortality and decision-making regarding polytraumatized pediatric patients. 


\section{Acknowledgment}

I would like to thank my colleagues in Tanta University Emergency Hospital, for my internship and for their wonderful cooperation for the study. I would like to express my gratitude to parents of my work whose expertise, understanding, and patience, added considerably to my graduate experience.

\section{Financial support and sponsorship}

Nil.

\section{Conflicts of interest}

There are no conflicts of interest.

\section{References}

1. Gilbert JC, Arbesman MC. Pediatric injury scoring and triage methodology. In: Ziegler MM, Azizkhan RG, Weber TR, editors. Operative Pediatric Surgery. $1^{\text {st }}$ ed. New York, United States of America: McGraw-Hill Professional; 2003. p. 1089-95.

2. Marcin JP, Pollack MM. Triage scoring systems, severity of illness measures, and mortality prediction models in pediatric trauma. Crit Care Med 2002;30 11 Suppl: S457-67.

3. Furnival RA, Schunk JE. ABCs of scoring systems for pediatric trauma. Pediatr Emerg Care 1999;15:215-23.

4. Borgman MA, Maegele M, Wade CE, Blackbourne LH, Spinella PC. Pediatric trauma BIG score: Predicting mortality in children after military and civilian trauma. Pediatries 2011;127:e892-7.

5. Vavilala MS, Dunbar PJ, Rivara FP, Lam AM. Coagulopathy predicts poor outcome following head injury in children less than 16 years of age. J Neurosurg Anesthesiol 2001;13:13-8.

6. Holcomb JB, McMullin NR, Pearse L, Caruso J, Wade CE, Oetjen-Gerdes L, et al. Causes of death in U.S. special operations forces in the global war on terrorism: 2001-2004. Ann Surg 2007;245:986-91.

7. Shah K, Rabrich J. Essential emergency trauma. Emerg Med J 2011;978:111-6.

8. Khothari CR, editor. Research Methodology, Methods and Techniques. $2^{\text {nd }}$ ed. New Delhi: New Age International; 2012. p. 95-7.

9. Bunn F, Kwan I, Roberts I. Effectiveness of Prehospital trauma care, Cochrane Injuries Group, Public health intervention Search Unit, Department of Epidemiology \& Population Health, London School of Hygiene and Tropical Medicine. Available from: http://www. cochrane-injuries.lshtm.ac.uk. [Last accessed on 2001 Oct 05].

10. Fiorentino JA, Molise C, Stach P, Cinder P, Solla MM, Hoffman E, et al. Pediatric trauma. Epidemiological study among patients admitted to Hospital de Niños "Ricardo Gutiérrez". Arch Argent Pediatr 2015;113:12-20, I-V.
11. Derakhshanfar H, Hatamabadi H, Karimian K. The prognosis of trauma among children and the factors contributing to it the Road Traffic Injuries Research Network. Health 2012;4:212-5. Available from: http://www.rtirn..net/. [Last accessed on 2012 Dec 21].

12. Letts M, Davidson D, Lapner P. Multiple trauma in children: Predicting outcome and long-term results. Can J Surg 2002;45:126-31.

13. Nakayama DK, Copes WS, Saceo WJ. The effect of patient age upon survival in pediatric trauma. J Trauma 1991;31:1521-6.

14. Vallipakorn SA, Plitapolkarnpim A, Suriyawongpaisal P, Techakamolsuk P, Smith GA, Thakkinstian A. Risk prediction score for death of traumatised and injured children. BMC Pediatr 2014;14:60.

15. Kincaid EH, Chang MC, Letton RW, Chen JG, Meredith JW Admission base deficit in pediatric trauma: A study using the National Trauma Data Bank. J Trauma 2001;51:332-5.

16. Randolph LC, Takacs M, Davis KA. Resuscitation in the pediatric trauma population: Admission base deficit remains an important prognostic indicator. J Trauma 2002;53:838-42.

17. Teasdale G, Jennett B. Assessment of coma and impaired consciousness. A practical scale. Lancet 1974:2:81-4.

18. Marcoux KK. Management of increased intracranial pressure in the critically ill child with an acute neurological injury. AACN Clin Issues 2005; 16:212-31.

19. Gill MR, Reiley DG, Green SM. Interrater reliability of Glasgow Coma Scale scores in the emergency department. Ann Emerg Med $2004 ; 43: 215-23$.

20. Hess JR, Lindell AL, Stansbury LG, Dutton RP, Scalea TM. The prevalence of abnormal results of conventional coagulation tests on admission to a trauma center. Transfusion 2009;49:34-9.

21. Verma A, Kole T. International normalized ratio as a predictor of mortality in trauma patients in India. World J Emerg Med 2014;5:192-5.

22. Narci A, Solak O, Turhan-Haktanir N, Ayçiçek A, Demir Y, Ela Y, et al. The prognostic importance of trauma scoring systems in pediatric patients. Pediatr Surg Int 2009;25:25-30.

23. Kaufmann CR, Maier RV, Rivara FP, Carrico CJ. Evaluation of the Pediatric Trauma Score. JAMA 1990;263:69-72.

24. Eichelberger MR, Gotschall CS, Sacco WJ, Bowman LM, Mangubat EA, Lowenstein AD. A comparison of the trauma score, the revised trauma score, and the pediatric trauma score. Ann Emerg Med 1989;18:1053-8.

25. Osler T, Baker SP, Long W. A modification of the injury severity score that both improves accuracy and simplifies scoring. J Trauma 1997;43:922-5.

26. Sullivan T, Haider A, DiRusso SM, Nealon P, Shaukat A, Slim M. Prediction of mortality in pediatric trauma patients: New injury severity score outperforms injury severity score in the severely injured. J Trauma 2003;55:1083-7.

27. Brockamp T, Maegele M, Gaarder C, Goslings JC, Cohen MJ, Lefering $\mathrm{R}$, et al. Comparison of the predictive performance of the BIG, TRISS, and PS09 score in an adult trauma population derived from multiple international trauma registries. Crit Care 2013;17:R134. 